\title{
Optical properties of chromium-doped transparent alumina xerogels
}

\author{
V SARASWATI \\ Materials Development Laboratory, Indira Gandhi Centre for Atomic Research, \\ Kalpakkam 603 102, India \\ *Present address: Defence Metallurgical Research Laboratory, Kanchanbagh, Hyderabad \\ 500258 , India
}

MS received 27 January 1988; revised 24 June 1988

\begin{abstract}
Optical properties of chromium-doped transparent alumina xerogels have been studied in the ultraviolet, visible and near infra-red regions. The coordination, valence state and symmetry of crystal field around the transition metal ion is found to change in different transition phases of the xerogel in accordance with the earlier conclusion that the metal ion penetrates into the alumina matrix and occupies aluminium sites. In boehmite and $\alpha-\mathrm{Al}_{2} \mathrm{O}_{3}$ chromium is essentially in trivalent state, octahedrally coordinated, whereas in the transition $\gamma$ and $\delta$ phases tetrahedrally coordinated hexavalent state appears to be dominant. This agrees with the spinel structure expected for the transition phases.
\end{abstract}

Keywords. Optical properties; transparent alumina; doped alumina; xerogel alumina.

\section{Introduction}

In recent years gel-processed materials have evoked considerable interest as it has become feasible to prepare glass and transparent ceramics at low temperatures. Transparent porous alumina was first prepared by Yoldas (1975). Detailed structural and optical studies (Saraswati et al 1987) revealed that the boehmite xerogel and transition aluminas were partially disordered. As the xerogels are porous with large surface area they are reactive and water is adsorbed at the pores. With dehydration the oxygen network in boehmite undergoes a change in symmetry accompanied by structural changes. The optical method enables the determination of coordination and valence state of the transition metal ion and thereby aluminum if the metal ion were to take a substitutional position. The dopant ions can also monitor phase changes in the xerogels. An earlier study with copper as dopant (Saraswati and Ramarao 1987) indicated the formation of aquochloro complex at the surface. Varied techniques such as magnetic susceptibility, electron spin resonance and phosphorescence spectroscopy were used by Pott and McNicol (1972) to ascertain the oxidation and coordination of $\mathrm{Fe}^{3+}$ and $\mathrm{Mn}^{2+}$ ions on transition alumina supports. In this paper, the optical measurements such as absorption wavelength and extinction coefficients in chromium-doped alumina xerogels have been compared with the available ESR and optical data. Formation of surface complexes in boehmite and absorption differing from glassy or crystalline matrix seem to be the unique features for the alumina gels. Apart from the information on the gel matrix, coordination and valence state of chromium throw light on the solubility of metal ion in the widely used transition alumina catalyst supports.

\section{Preparation of xerogels}

Xerogel monoliths were prepared from aluminum isopropoxide through hot hydro- 
lysis and chemical polymerization at $80^{\circ} \mathrm{C}$. Hydrochloric acid was used as a catalyst. The $\mathrm{pH}$ of the solution was about 3 when gelling started. The microstructure and properties of dry gel depend upon the process parameters such as the amount of water and acid added. The optimum molar ratio for alkoxide, water and acid was found to be $1: 100: 0 \cdot 3$ for obtaining crack-free clear monoliths called xerogels. Slow evaporation of gel in flat dish produced monolithic xerogels, which are transparent and porous solid materials. The dry gels ranged in thickness from 0.1 to $0.5 \mathrm{~mm}$ and had a transmission better than $70 \%$. The transition metal was introduced as powder, wire or salt solution during gelation. A spontaneous change in colour was observed. The wire or powder was removed and the solution was rehydrolysed. The gel powder with high chromium concentration was prepared as above and for smaller chromium concentration the xerogels were prepared by mixing the above gel with undoped alumina gel powder. The dopant concentration was estimated spectrochemically. The monoliths were colourless when the concentration was $<1000 \mathrm{ppm}$. For higher concentrations the xerogels were green in colour. They became yellowish on heating and with dehydration of water. The transition to other phases occurred at $400^{\circ} \mathrm{C}\left(\gamma\right.$ phase), $900^{\circ} \mathrm{C}$ ( $\delta$ phase) and $1150^{\circ} \mathrm{C}(\alpha$ phase). The $\alpha$ phase was the crystalline phase similar in structure to corundum as confirmed by $X$-ray diffraction (XRD). Boehmite and transition phases were disordered. These details are discussed elsewhere (Saraswati et al 1987). The doping did not alter XRD or IR results and the xerogel remained transparent up to a heating temperature of $1000^{\circ} \mathrm{C}$ and became opaque above it.

\section{Optical measurements and results}

A Hitachi spectrophotometer was used to record the transmission and absorption spectrum in the range 0.2 to $2.5 \mu \mathrm{m}$. The reference was either the beam or undoped

Table 1. Molar absorptivity in chromium doped alumina xerogels.

\begin{tabular}{|c|c|c|c|c|c|}
\hline $\begin{array}{c}\text { Alumina } \\
\text { phase }\end{array}$ & $\begin{array}{l}\text { Conc. } \\
\text { (wt. \%) }\end{array}$ & Colour & $\begin{array}{c}\text { Thickness } \\
(\mathrm{mm})\end{array}$ & $\begin{array}{c}\text { Absorbtion } \\
\text { peak at } \\
(\mathrm{nm}, \pm 5)\end{array}$ & $\underset{\varepsilon}{\varepsilon}\left(\right.$ Litre $\left.\mathrm{nol}^{-1} \mathrm{~cm}^{-1}\right)$ \\
\hline Boehmite & $6 \cdot 7$ & Green & 0.14 & $\begin{array}{l}430 \\
590\end{array}$ & $\begin{array}{l}138 \\
101\end{array}$ \\
\hline Boehmite & 0.28 & Light green & 0.48 & $\begin{array}{l}430 \\
590\end{array}$ & $\begin{array}{l}56 \\
73\end{array}$ \\
\hline Boehmite & $0 \cdot 1$ & None & 0.1 & None & - \\
\hline$y-\mathrm{Al}_{2} \mathrm{O}_{3}(400 / 4 \mathrm{~h})$ & $6 \cdot 7$ & Brownish & $0 \cdot 1$ & $\begin{array}{c}\text { Flat in range } \\
210-465\end{array}$ & - \\
\hline$\gamma-\mathrm{Al}_{2} \mathrm{O}_{3}(700 / 4 \mathrm{~h})$ & 6.7 & Yellowish green & $0 \cdot 1$ & 565 & 16 \\
\hline$\gamma-\mathrm{Al}_{2} \mathrm{O}_{3}(700 / 4 \mathrm{~h})$ & 0.28 & Yellowish green & $0 \cdot 4$ & $\begin{array}{l}560 \\
370\end{array}$ & $\begin{array}{r}22 \\
4400\end{array}$ \\
\hline$\gamma-\mathrm{Al}_{2} \mathrm{O}_{3}(700 / 4 \mathrm{~h})$ & $0-1$ & - & 0.1 & 370 & 4156 \\
\hline$\delta-\mathrm{Al}_{2} \mathrm{O}_{3}(950 / 6 \mathrm{~h})$ & 6.7 & Yellowish green & 0.09 & $\begin{array}{l}565 \\
370\end{array}$ & $\begin{array}{l}21 \\
78\end{array}$ \\
\hline$\delta-\mathrm{Al}_{2} \mathrm{O}_{3}(950 / 6 \mathrm{~h})$ & 0.28 & Yellowish green & 0.4 & $\begin{array}{l}560 \\
370\end{array}$ & $\begin{array}{r}22 \\
762\end{array}$ \\
\hline$\delta-\mathrm{Al}_{2} \mathrm{O}_{3}(950 / 6 \mathrm{~h})$ & 0.1 & 一 & 0.09 & 370 & 4800 \\
\hline
\end{tabular}


alumina monolith. Owing to the fine size of particles the surface was smooth and glossy despite porosity. The transmission was $>70 \%$ in the visible and near infrared range of wavelengths. Absorption at $1.94 \mu \mathrm{m}$ gave an estimate of the water content, which was $5-6 \mathrm{wt} \%$ in boehmite, taking extinction coefficient for water as 67. The water content was much less in the transition phase alumina. The absorption due to trivalent $\mathrm{Cr}$ was in the visible at about 430 and $590 \mathrm{~nm}$ for boehmite. Hexavalent chromium showed absorption typically at 270 and $370 \mathrm{~nm}$ (Nath et al 1965). The extinction coefficient was calculated using the formula $\varepsilon=2.303 \mathrm{OD} c^{-1}$ $x^{-1}$ (litres $\mathrm{mol}^{-1} \mathrm{~cm}^{-1}$ ) where OD is the optical density, $c$ the concentration in litre per mole and $x$ the thickness of the specimen. From the details shown in table 1 it can be inferred that (i) in the boehmite phase, trivalent state alone is observed for all concentrations of chromium studied, (ii) with decrease in concentration the peak corresponding to trivalent state becomes less intense ( $\varepsilon$ is lower), (iii) in $\gamma$ and $\delta$ alumina phases, hexavalent state becomes prominent ( $\varepsilon$ values are higher) for low chromium concentrations, (iv) the absorption shifts to lower wavelength for $\mathrm{Cr}$ trivalent in $\gamma$ and $\delta$ alumina and (v) in the $\delta$ phase, higher $\mathrm{Cr}$ concentration tends to have lower $\varepsilon$ for hexavalent state. These points will now be discussed in greater detail.

\section{Discussion}

\subsection{Chromium in boehmite xerogel}

The xerogels and dry gel powder consist of fine particles $(8.5 \mathrm{~nm})$, a large porosity $(\sim 60 \%)$ and a large surface area. The diffuse broad bands in XRD could be

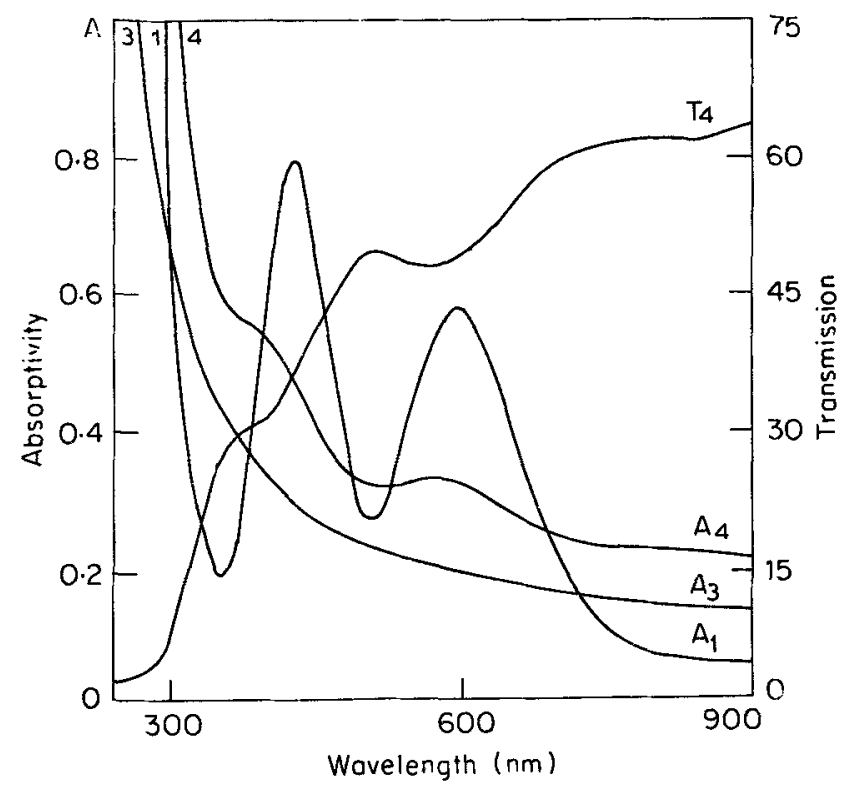

Figure 1. Absorption (A) in Cr-doped boehmite xerogels. 1, 3,4 are samples with 6, 7,0-28, $0.1 \mathrm{wt} \% \mathrm{Cr}$ respectively. Their thickness are given in table 1 . 
assigned to the ultrafine size and porosity. The optical absorption edge occurred at $240 \mathrm{~nm}(5 \cdot 1 \mathrm{eV})$ similar to amorphous alumina. Hence, the absorption in the visible was compared with trivalent chromium in glasses. Experimentally it was observed that in boehmite (i) optical absorption occurred at 590 and $435 \mathrm{~nm}$ whereas in glasses they occur at $650 \mathrm{~nm}$ and $410 \mathrm{~nm}$, (ii) the fine structure observed for $650 \mathrm{~nm}$ line in glasses was absent and (iii) the extinction coefficient varied with concentration whereas it should be invariant (figure 1).

Sakka (1983) doped silica gel solution with transition metal nitrates up to $40 \mathrm{wt} \%$ and thin films coated on glass plates were used for optical absorption. As they were heated they assumed the composition $\mathrm{SiO}_{2} . R_{m} \mathrm{O}_{n}$ where $R$ is the transition metal ion. The absorption for $\mathrm{Cr}^{3+}$ was found at $650,410 \mathrm{~nm}$ similar to oxide glasses. Earlier, Schultz (1974) observed only the absorption in the ultraviolet at 370 due to $\mathrm{Cr}^{6+}$. This could have been due to concentration differences. High surface area oxides have been known to adsorb transition metal ions and form clusters at surface (Bleam and $\mathrm{McBride}$ 1986). In ESR of $\mathrm{Cu}^{2+}$ adsorbed on silica at $\mathrm{pH} \sim 4$, the coordination of $\mathrm{Cu}^{2+}$ was attributed largely to $\mathrm{H}_{2} \mathrm{O}$ as in aqueous solutions but with the metal ion rigidly bound to surface as silanol group (Takahashi and Tanaka 1987). Furthermore, ESR and ultraviolet spectra of $\mathrm{Cu}^{2+}$ on alumina gels are found to be different from $\mathrm{Cu}^{2+}$ on silica gel in that the ions occupy strong-ligand equatorial position and bind to one or more $\mathrm{Al}-\mathrm{O}$ groups (Huang and Stumm 1986). We can visualize for chromium as in figure 2.

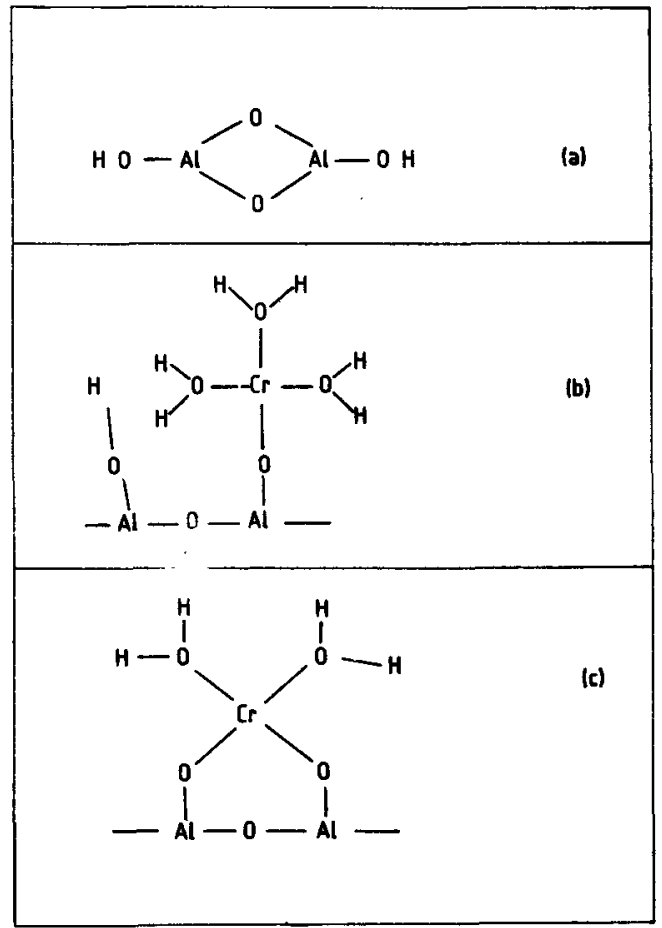

Figure 2. Probable binding of chromium complex to surface sites on porous alumina hydrate a. aluminium oxyhydroxide molecule b. coordination of $\mathrm{Cr}$ complex to one site c. coordination to two sites on alumina. 
Adsorption of transition metal ions and formation of aqueous complexes at surface sites can account for the optical absorption at $590 \mathrm{~nm}$ and $430 \mathrm{~nm}$. In aqueous potassium chromate the absorption is at $575,405 \mathrm{~nm}$ and in glasses at $650,410 \mathrm{~nm}$.

$\mathrm{Cr}^{3+}$ ion has a $d^{3}$ configuration and three spin-allowed transitions are predicted $4 A_{2}(F) \rightarrow 4 T_{2}(F), \quad 4 A_{2}(F) \rightarrow 4 T_{1}(F)$ and $4 A_{2}(F) \rightarrow 4 T_{1}(P)$. The first two are commonly observed in the range $700-550 \mathrm{~nm}$ and $400-500 \mathrm{~nm}$ in oxide media. The third is usually hidden by charge transfer. In the transition $4 A_{2}(F) \rightarrow 4 T_{2}(F)$ at $650 \mathrm{~nm}$ for oxide glass a fine structure was observed which was attributed by Bates (1962) to the crossing of energy levels $4 T_{2}(F)$ with $2 T_{1}(G)$ and $2 E(G)$ at ligand field of glass oxide ions. In dilute solutions and in chloride glasses in which the ligand field is higher or lower than oxide glasses the fine structure is absent because the quadruplet and doublet energy states are separated out and no mixing takes place. In our case as most of the ligands are water molecules the ligand field is higher than the crossing over point and there is no fine structure. The absorption in the visible at 590 and $435 \mathrm{~nm}$ indicates trivalent chromium in octahedral environment. The wavelength of absorption and the intensities for the two transitions are dependent on the metal ligand distance, the nature of bonding and the distortion of octahedron. No quantitative calculation is possible as all the above data are absent for gel medium, which has a certain amount of water but not aqueous and has disorder though not glassy. In crystalline $\mathrm{Cr}_{2} \mathrm{O}_{3}$ the visible range absorption occur at 595, $435 \mathrm{~nm}$ and $\mathrm{Cr}-\mathrm{O}$ distance is $\sim 2 \AA$ (McClure 1963). In ruby $\left(\mathrm{Cr}^{3+}\right.$ in $\mathrm{Al}_{2} \mathrm{O}_{3}$ ) the absorption depends on the $\mathrm{Cr}$ content and for $1 \% \mathrm{Cr}_{2} \mathrm{O}_{3}$ it is at 550 , $388 \mathrm{~nm}$ and $\mathrm{Al}-\mathrm{O}$ distances are 1.94 $\AA$. Cr-O bond is ionic in both. Comparing the results from table 1 , it appears that the ligands surrounding chromium are partly oxygen and partly water as in figure 1. The amount of water in xerogel as calculated from absorption at $1.94 \mu \mathrm{m}$ was about $5-6 \mathrm{wt} \%$ for the copper- and iron-doped gels $(0.9 \mathrm{wt} \%$ dopant $)$ in the boehmite phase and much less for transition aluminas. When the $\mathrm{Cr}$ concentration is lower the nature of surface complex formed could be different and this probably is reflected in the lowering of extinction coefficient with concentration. Any shift in absorption wavelength due to this change could not be measured as the intensities were low. Bleam and McBride (1986) also found that the hydroxyl content of surface clusters depend on the $\mathrm{pH}$ of solutions and the concentration of transition metal ions. We had noted earlier that the absorption wavelength and extinction coefficients of $\mathrm{Cu}^{2+}$ on alumina gels depend strongly on the acidity of gel solution and the concentration of copper (figure 3).

\subsection{Chromium in $\gamma-\mathrm{Al}_{2} \mathrm{O}_{3}$}

The boehmite xerogel heated between 400 and $900^{\circ} \mathrm{C}$ produces the $\gamma$ alumina phase. The green and colourless xerogels turned yellowish on heating and there was a slight change in thickness due to dehydration. Figure 4 shows a weak $435 \mathrm{~nm}$ peak which may be due to small amount of unconverted boehmite in the xerogel heated at $400^{\circ}$ whereas the one heated at $700^{\circ}$ was different though both showed identical XRD corresponding to the $\gamma$ phase. It can be seen from table 1 that both hexavalent and trivalent chromium are present. The hexavalent peak is intense with $\varepsilon=4150$ for low concentration. The hexavalent state is marked by lines at 370 and $270 \mathrm{~nm}$, from $\left(\mathrm{CrO}_{4}\right)^{2-}$ showing a tetrahedral coordination. The value of $\varepsilon$ is similar to that in 


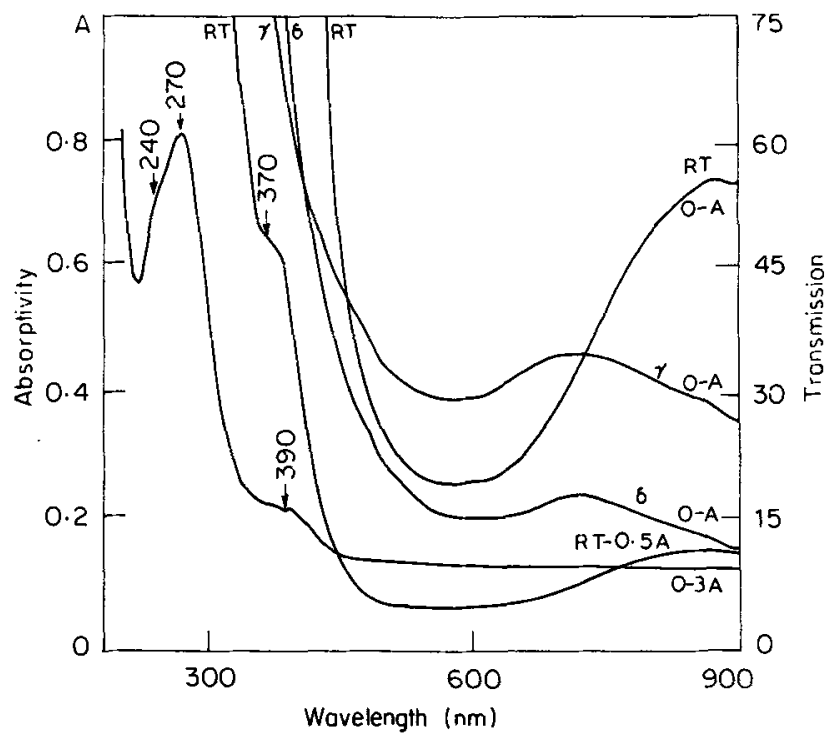

Figure 3. Absorption spectra in $\mathrm{Cu}(0.85 \mathrm{wt} \%)$-doped xerogels $(\mathrm{pH}=2)$ in boehmite and alumina $(\gamma, \delta)$ phase.

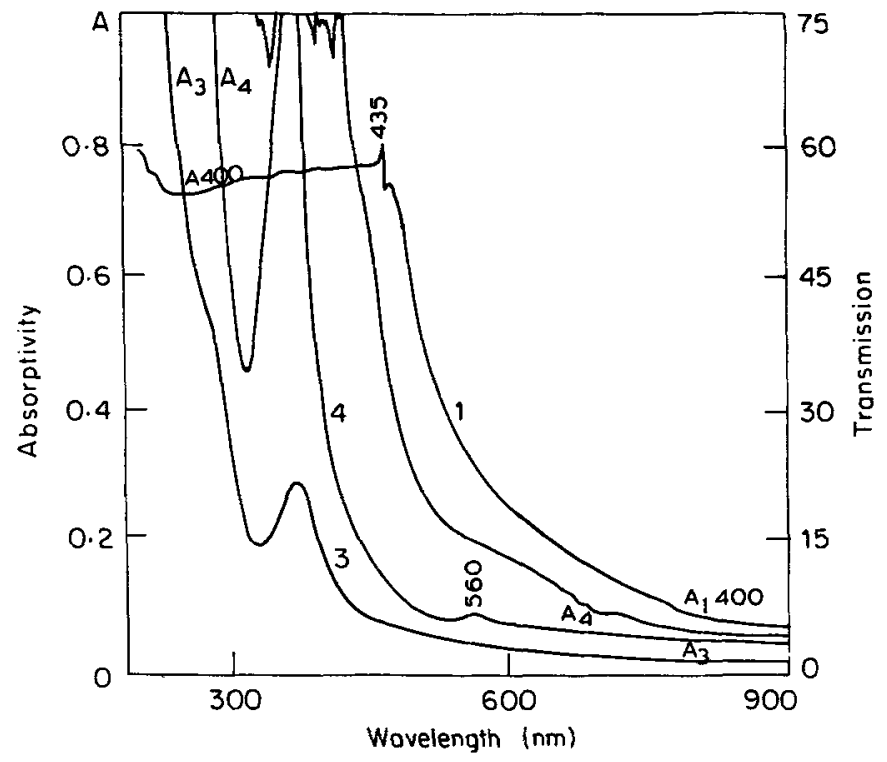

Figure 4. Absorption in $\mathrm{Cr}$-doped alumina xerogel in $\gamma$ phase.

oxide glasses (Nath et al 1965). Similarly the trivalent chromium had $\varepsilon$ consistent with glasses, indicating that in the $\gamma$ alumina phase chromium is surrounded by $O$ as ligands at distance $\sim 1.94 \AA$ as for Al-O in alumina. The absorption at $560 \mathrm{~nm}$ is also similar to ruby. Thus it appears that on heating the metal ions penetrate into the bulk and occupy the aluminium position. Pott and McNicol (1972) also observed from magnetic susceptibility measurements that heating above $400^{\circ} \mathrm{C}$ 
$\mathrm{Fe}^{3+}$ penetrates into the bulk in $\gamma-\mathrm{Al}_{2} \mathrm{O}_{3}$. This was further confirmed with ESR and phosphorescence. Apart from surface defects and porosity there are vacant tetrahedral sites in the transition aluminas. When the ionic radius is smaller as for $\mathrm{Cr}^{6+}(0.037 \mathrm{~nm})$ the occupation of a vacant aluminium $(0.047 \mathrm{~nm})$ site is more probable. Hence the hexavalent tetrahedral state is probably dominant at lower concentrations. The oxidation of $\mathrm{Cr}^{3+}$ to $\mathrm{Cr}^{6+}$ in the $\gamma$ phase could also be inferred from the difference in the recordings of xerogels heated at $400^{\circ}$ and $700^{\circ} \mathrm{C}$ (figure 5). The oxidation reaction for glasses are written as

$$
\begin{aligned}
& \mathrm{Cr}^{3+}+3 / 4 \mathrm{O}_{2} \longrightarrow \mathrm{Cr}^{6+}+3 / 2 \mathrm{O}^{2-} \\
& 1 / 2 \mathrm{Cr}_{2} \mathrm{O}_{3}+3 / 4 \mathrm{O}_{2} \longrightarrow \mathrm{CrO}_{3}
\end{aligned}
$$

The penetration into the bulk is probably the reason for constant $\varepsilon$ values in $\gamma$ $\mathrm{Al}_{2} \mathrm{O}_{3}$ phase.

\subsection{Chromium in $\delta \mathrm{Al}_{2} \mathrm{O}_{3}$}

The coexistence of trivalent and hexavalent states as in $\delta \mathrm{Al}_{2} \mathrm{O}_{3}$ has been observed. $\varepsilon$ values are again found to be dependent on concentration. Since the samples were heated at $\sim 1000^{\circ} \mathrm{C}$ a small amount of $\alpha$ phase (crystalline) could still form and as this would depend on the concentration of dopant there could be a dependence on it. For concentration $>1000 \mathrm{ppm}, \varepsilon$ values were high and lines intense. Another possibility is that with increased $\mathrm{Cr}$ concentration there will be distortion of the tetrahedron which could again disturb $\varepsilon$ values. The presence of tetrahedrally coordinated $\mathrm{Cr}^{6+}$ in the bulk in the $\gamma$ and $\delta$ phases and not in boehmite supports the spinel structure for the transition alumina phases.

\subsection{Chromium in $\alpha-\mathrm{Al}_{2} \mathrm{O}_{3}$}

When heated above $1150^{\circ} \mathrm{C}$ the xerogel turned opaque and pink in colour similar

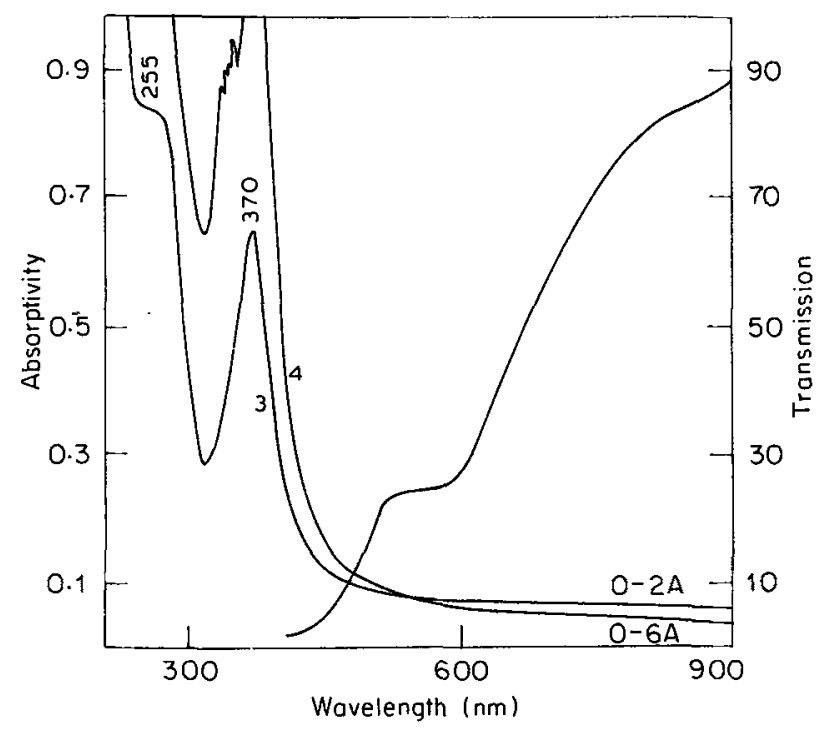

Figure 5. Absorption and transmission in Cr-doped alumina in $\delta$ phase. 
to ruby. No optical measurements were carried out. The opacity is ascribed to the coarsening of particles and nucleation of the crystalline phase. The XRD was similar to crystalline alumina though the lattice volume was slightly higher for the $6 \mathrm{wt} \%$ xerogel. Hence a solid solution of $\mathrm{Cr}^{3+}$ could be inferred. The trivalent state of $\mathrm{Cr}$ in $\alpha \mathrm{Al}_{2} \mathrm{O}_{3}$ has been confirmed through ESR.

Thus in going through the transition, boehmite $\rightarrow \gamma \rightarrow \delta \rightarrow \alpha \quad \mathrm{Al}_{2} \mathrm{O}_{3}$, the valence state of $\mathrm{Cr}$ changes from $\mathrm{Cr}^{3+} \rightarrow \mathrm{Cr}^{6+} \rightarrow \mathrm{Cr}^{3+}$. The oxidation of $\mathrm{Cr}^{3+}$ to $\mathrm{Cr}^{6+}$ could be related to the reduced stability of $\mathrm{Cr}^{3+}$ ion as $\mathrm{H}_{2} \mathrm{O}$ ligands were removed and the reduction $\mathrm{Cr}^{6+} \rightarrow \mathrm{Cr}^{3+}$ is related to the crystallization of $\alpha \mathrm{Al}_{2} \mathrm{O}_{3}$ as pores are removed and there is loss of surface area. A similar oxidation reduction cycle associated with dehydration and surface area reduction was observed in chromium oxide gels.

The presence or otherwise of $\mathrm{AlO}_{4}$ and $\mathrm{AlO}_{6}$ units could be inferred through IR and Raman spectra. IR in the transition phases of alumina showed broad featureless band (Saraswati et al 1987) whereas a distinct absorption corresponding to $\mathrm{AlO}_{6}$ could be seen in boehmite and $\alpha$ alumina phases. The Raman spectrum similarly was devoid of any absorption in $\gamma$ and $\delta$ alumina whereas distinct modes could be observed for boehmite and $\alpha$ alumina. It needs to be mentioned here that optical data have given a better insight into the binding at the surface through $\mathrm{Cu}$ and $\mathrm{Cr}$ doping and the spinel structure for $\gamma$ and $\delta$ alumina phases.

\section{Conclusions}

It is concluded that dopant chromium takes a trivalent or hexavalent state depending on the concentration and the phase of alumina. The formation of complexes and their binding to the surface of porous xerogel are discussed and compared with glasses and crystalline media. The oxidation-reduction cycle of $\mathrm{Cr}^{3+}$ is associated with oxygen network changes as water is removed and crystallization takes place in alumina. The penetration of chromium into the bulk probably takes place via the vacant tetrahedral and octahedral sites of the spinel structured $\gamma$ and $\delta$ alumina.

\section{Acknowledgement}

The assistance and help of Shri G V Rama Rao in recording the optical spectra is gratefully acknowledged.

\section{References}

Bates T 1962 Modern aspects in vitreous state (London: Butterworths)

Bleam W F and McBride M B 1986 J. Colloid Interface Sci. 110335

Huang C P and Stumm W 1986 J. Colloid Interface Sci. 11325

Lippens B C and Deboer J H 1964 Acta. Crystallogr. 171312

Mcclure D S 1963 Physics and chemistry of ceramics (ed.) C Klingsberg (New York: Gordon and Breach) p 110

Nath R, Paul A and Douglas R W 1965 Phys. Chem. Glasses 6203

Pott G T and McNicol B D 1972 Surface chemistry of oxides (London: The Faraday Society) p. 121

Sakka S 1983 J. Mater. Sci. Lett. 2395 
Saraswati V and Ramarao G V 1987 Bull. Mater. Sci. 9193

Saraswati V, Rao G V N and Ramarao G V 1987 J. Mater. Sci. 222529

Schultz P 1974 J. Am. Ceram. Soc. 57309

Takahashi T and Tanaka K 1987 J. Colloid Interface Sci. 120419

Yoldas B 1975 Am. Ceram. Soc. Bull. 54289 